Augusto Quintana Benavides

\title{
Reformas a las bases de la institucionalidad: Entre lo superfluo, el contrabando y la inocencia ${ }^{1}$
}

Bodhidharma, considerado como el primer patriarca Zen, fue el hombre que llevó el budismo de la India a China en el siglo V. Cuando decidió regresar a la patria, reunió en torno a si a sus discipulos chinos, con el fin de nombrar a quien debia sucederle. Para ello sometió a prueba sus poderes de percepción, haciendo a cada uno de ellos la misma pregunta: "Qué es la verdad?"

Respondió Dofuku: La verdad es lo que está más allá de la afirmación y la negación. Yle dijo Bodhidharma: "Tú tienes mi misma piel".

La devota Soji respondio: La verdad es como la visión que tuvo Anand del pais de Buda: una visión que duró un instante y perduró para siempre. Yle dijo Bodhidharma: "Tú tienes mi misma carne".

Respondió Doiku: Los cuatro elementos-viento, agua, tierra y fuego- están vacios. La verdad es nada. Y le dijo Bodhidharma: "Tú tienes mis mismos huesos".

Finalmente, el Maestro miró a Eka, que hizo una profunda reverencia, sonrió y se quedó en silencio. Yle dijo Bodhidharma: "Tú tienes mi misma médula".

(Anthony de Mello, s.j. ${ }^{-}$)

* Profesor de

Derecho

Constitucional

Universidad de

Chile.

3. Es de justicia agradecer la colaboración que the prestara MARÍA JOSÉ GATICA LOPEZ, abogada de la Universidad de Chile, especialmente en la redacción del capitulo relativo a los principios de transparencia y publicidad. Anthony de MELLO: "La oración de la rana" (Editorial Sal rérrea, España, 16a edición, 1988, Vol. 1, pág. 2678). 
Las modificaciones que la Ley No 20.050, de 2005, introduce al Capítulo I de la Constitución ${ }^{3}$ no se cuentan entre las más comentadas por políticos y juristas. Si nos atenemos a la deliberación que la antecedió, sin duda las reformas a las Bases de la Institucionalidad palidecen, por ejemplo, frente a la democratización del Senado de la República y las enmiendas a la justicia constitucional. Esta aseveración podría ser particularmente patente tratándose de la modificación al artículo $3^{\circ}$. Empero, como en toda obra de ingeniería, las reformas que se efectúan a los cimientos de una obra, por definición no pueden ser menores y, ciertamente, las enmiendas a las bases de la institucionalidad están llamadas, a veces con ignorancia de sus autores, a suscitar transformaciones muy relevantes en la vida nacional. Creemos que así ocurrirá con el fortalecimiento de los principios de igualdad y de solidaridad en el ámbito territorial; la salomónica asignación a todos los órganos del Estado de la función de "garantizar el orden institucional de la República" y, a no dudar, la consagración constitucional de los principios de probidad y de transparencia, como asimismo el reforzamiento y extensión del deber de fundamentar los actos y resoluciones de los órganos del Estado.

En suma todas estas enmiendas apuntan al fortalecimiento del Estado Democrático y Constitucional de Derecho, en sintonía con la idea de que el principio de juridicidad no importa exclusivamente la sujeción formal a una norma jurídica sino que también a un conjunto de principios y valores consagrados literalmente en la norma constitucional o que se contienen implícitamente en su formulación. En efecto, permítasenos insinuar que esta reforma constitucional, en la sección que nos corresponde analizar, es un paso adelante hacia una idea más sustantiva del derecho, dejando atrás una modalidad de positivismo jurídico que se agota en el mero formalismo normativo. El lector avezado en las ciencias del derecho podrá entender perfectamente bien este alcance, el cual la jurisprudencia -a no dudar- con el correr del tiempo revelará en toda su magnitud.

Para desarrollar este alcance examinaremos la literalidad de las reformas. En todo caso y con humildad, estimamos que el impacto auténtico de las reformas constitucionales introducidas por la Ley de Reforma Constitucional N²0.050 a las Bases de

Por cierto, la Ley No 20.050 es, técnicamente, una ley de reforma constitucional y no la sanción de una Nueva Constitución, como asegurara el Presidente Lagos al momento de promulgar el texto vigente. En efecto, para el autor de estas lineas la Constitución aprobada abrumadoramente por el pueblo de Chile en el año 1989 y que entró a regir el 11 de marzo de 1990 es, a no dudar, la convención constitucional que, con sus numerosas enmiendas, contiene las bases estructurates de nuestra convivencia social. Así, a nuestro juicio, no es dable hablar de Constitución de 1980 o de 2005, pues la única Constitución que ha aprobado libre y soberanamente el pueblo de Chile es la Constitución que se sometió a su consideración plebiscitaria el año 1989. Asimismo, permítasenos terciar frente a otra polémica relativa a la autoría intelectual de nuestra Carta Fundamental, afirmando que ésta no es la Constitución del dúo Pinochet y Jaime Guzmán ni la de Ricardo Lagos y José Miguel Insulza. Las Constituciones, las serias y democráticas, no tienen parernidad radicada en persona alguna, por muy brillante que haya sido su aporte a una obra colectiva, pues una auténtica Constitución o es del pueblo que la refrenda o, en caso contrario, deja de ser Constitución y se yergue en una técnica impositiva o una seudo legitimación del crudo poder político. 
la Institucionalidad habrá de estarse al tiempo y al comportamiento de los órganos del Estado y los ciudadanos. En este punto cobra fuerza la guía de Anthony de Mello, s.j., en cuya virtud la verdad se expresa mejor en el silencio, según la "respuesta" que Eka brindara a la pregunta de Bodhidharma.

\section{Modificaciones al Artículo $3^{\circ}$.}

"... hay ocasiones en la vida en que una urgente necesidad de salir del marasmo de la indecisión, de hacer algo, sea lo que sea, aunque inútil aunque superfluo, es la última señal de capacidad volitiva que nos queda, ..." (José Saramago). ${ }^{4}$

Uno de los ángulos a partir de los cuales es posible estudiar nuestra historia constitucional es el dualismo entre el centralismo político y la autonomía regional. No pretendo al lector de estas líneas convencer acerca de cuánto ha impactado el centralismo político en la capacidad creadora de riqueza y de cultura de nuestro pueblo. Sí creemos que el artículo $3^{\circ}$ de la Constitución no refleja un consenso nacional. Su redacción, la anterior a la Ley No20.050 como la vigente, es expresión de una idea de concesión máxima que los partidarios del centralismo político -los hay, son muy relevantes políticamente $\mathrm{e}$, incluso, muchos de ellos son representantes de regiones en el Congreso Nacional- están abiertos a otorgar. Saramago, en la cita que preside este capítulo, lo explica muy bien: no es que estemos en presencia de un mero gatopardismo, es -más bien- expresión, empleando el lenguaje de Annold Toynbee, de una "némesis de la capacidad creadora" del pueblo de Chile.

Esta reforma constitucional, en lo que atañe a la disyuntiva entre centralismo político y una auténtica regionalización, entendida ésta como el florecimiento libre de las autonomías regionales, refleja la falta de voluntad de nuestras autoridades para abrir los espacios de libertad necesarios para que, a lo largo y ancho de nuestro territorio, se despliegue la inventiva y la creatividad de nuestro pueblo. El temor nuevamente anula a la libertad. Ortega y Gasset, en un discurso que pronuncia como Diputado ante las Cortes Constituyentes y en el cual aboga por la "descentralización mayor posible de funciones politicas y administrativas" , afirma la creencia de que este autonomismo "ofrece un horizonte ilimitado de libertad" . Naturalmente, la libertad que se reivindica es tanto para los habitantes de la Región Metropolitana como de las demás regiones del país.

4 José SARAMAGO: "El hombre duplicado" (Aguilar Chilena de Ediciones S.A., Santiago de Chile, 2a edición, 2003, pág. 299).

5 Discurso en las Cortes Constituyentes, en la noche del 25 a 26 de septiembre de 1931, publicado en José ORTEGA Y GASSET: “Discursos políticos” (Alianza Edirorial S.A., Madrid, 1990, primera reimpresión, pág. 172).

6 Ob. cit., pág. 175. 
En un artículo relativamente reciente $\mathrm{C}^{7}$ hablamos de una "transición inconclusa" que tiene como marco toda nuestra historia constitucional y que denota la ausencia de un liderazgo y de consensos adecuados para construir Comunidades Regionales Autónomas y Democráticas, punto en el cual culmina el proceso de descentralización política, estadio el cual no hemos podido construir en casi 200 años de historia constitucional. Por ello es que no apreciamos en la enmienda constitucional del año 2005 una excepción a esta impotencia colectiva. En otras palabras, la reforma constitucional del año 2005 es expresión de nuestra reiterada indecisión histórica de avanzar hacia horizontes más amplios de libertad y democracia.

En efecto, la reforma constitucional introduce dos modificaciones sustanciales ${ }^{8}$ al artículo $3^{\circ}$, ninguna de las cuales aborda con entereza y claridad este nudo gordiano del constitucionalismo criollo:

- En primer lugar, suprime de la redacción anterior la expresión "su territorio se divide en regiones", $\mathrm{y}$

- En segundo término, agrega un inciso nuevo que a la sazón dispone: "Los órganos del Estado promoverán el fortalecimiento de la regionalización del país y el desarrollo equitativo y solidario entre las regiones, provincias y comunas del territorio nacional'. Esta última norma permite un desglose entre el fortalecimiento de la regionalización y la consagración de los principios de equidad y solidaridad.

Examinaremos por separado estas modificaciones.

\section{1.- Supresión de la frase "su territorio se divide en regiones"}

La lectura del debate parlamentario no nos entrega muchas luces sobre por qué se suprimió esta frase. Lo cierto es que el Senado, durante el primer trámite constitucional, aprobó una redacción que recogía la idea de la división territorial en un nuevo inciso tercero del artículo $3^{\circ}$, en los siguientes términos: "Los órganos del Estado promoverán la regionalización del pais y el desarrollo equitativo entre las regiones, provincias y comunas en que se divide el territorio nacional." . Parte de esta redacción, la relativa a la frase final ("entre las regiones, provincias y comunas en que se divide el territorio

Augusto QUINTANA BENAVIDES: “Estatuto constitucional de las regiones: una transición inconclusa”, publicado en el libro colectivo "El futuro de la descentralización. Algunas visiones académicas, políticas y sociales" (Instituto Chileno de Estudios Humanisticos, Santiago de Chile, 2003, págs. 30 a 54, inclusives).

s Existen otras dos modificaciones que se contienen en el actual inciso primeto del artículo en comento y que tienen por finalidad dar una redacción más hilvanada a la oración y un uso más propio de los términos, respectivamente: i) Se especifica en materia de descentralización y desconcentración que ello incide en la administración "del Estado", aunque del texto anterior se infería igual sentido, y ii) existe un cambio en la preposición empleada en la frase final del inciso ("de", en vez de "en"), de manera que la administración del Estado será funcional y territorialmente descentralizada , o desconcentrada en su caso, "de conformidad con la ley".

Ver Oficio No24.342, de 11 de noviembre de 2004 del Senado a la Cámara de Diputados, en www.congreso.cl. 
nacional') se origina en una Indicación formulada por el Senador señor Horvath ${ }^{10}$, la cual sin embargo conservaba en su inciso primero la expresión ahora suprimida (" $s u$ territorio se divide en regiones").

La Cámara de Diputados, en el segundo trámite constitucional, sustituyó el referido inciso tercero del artículo $3^{\circ}$, para alterar el objeto del deber que se impone al Estado y con la finalidad de consagrar el principio de solidaridad territorial, que comentaremos más adelante, sin modificar el texto aprobado por el Senado en la parte que aquí nos interesa.

Así, la redacción final que recoge el actual artículo $3^{\circ}$ importa dos modificaciones sustanciales al texto constitucional anterior:

a) En primer lugar, por cuanto ya no es el territorio "del Estado" el que se divide en diferentes unidades sino el territorio "nacional". Es claro que para los redactores de esta norma constitucional, aparentemente sin mucha conciencia del cambio que se introduce, no debiera ser más que una mera modificación "linguística", sin mayor trascendencia. De esta opinión pareciera ser el profesor Domingo Hernández, quien plantea que esta enmienda "no reviste trascendencia conceptual"11. La razón que esgrime el profesor Hernández es que el antiguo artículo 99, hoy 110, también recogía esta división territorial en regiones, por lo que se tornaba redundante la mención que, en el mismo sentido, hacía el artículo $3^{\circ}$. No compartimos esta postura, pues el alcance de la división territorial del antiguo artículo 99 era y es más restringido, esto es, para el sólo efecto del gobierno y administración interior del Estado. Es más, la trascendencia conceptual de esta enmienda queda patente en tanto no es lo mismo decir que "el Estado" se divide en regiones, a decir que el territorio "nacional" se divide en diversas unidades territoriales. En estricto sentido, nos parece más apropiada la idea que recoge el nuevo texto constitucional, pues la noción del territorio como un elemento del Estado es propio de ciertas teorías del Estado de la primera mitad del siglo XX que nos parecen particularmente desafortunadas y superadas. En efecto, el territorio -con todas las extensiones que este concepto posee conforme al Derecho Internacional- no puede pertenecer a uno de los sujetos constitucionales, es decir, al Estado. El territorio, en estricto sentido, no le pertenece al Estado ni éste podría "dividirse" territorialmente. Por el contrario, el territorio -si es que fuere susceptible de apropiación- sólo podría asignarse en titularidad a la comunidad de personas que lo habitan o residen permanentemente en él. De este modo, tiene sentido

Indicación No18. Véase en www.congreso.cl.

Domingo HERNÁNDEZ EMPARANZA: "Notas sobre algunos aspectos de la reforma a las bases de la institucionalidad, en la reforma constitucional de 2005: Regionalización, probidad y publicidad de actos", artículo publicado en Humberto Nogueira Alcalá (coordinador): "La Constitución Reformada de 2005" (Centro de Estudios Constitucionales de la Universidad de Talca - Librotecria, Santiago de Chile, 2005, pág. 23). 
emplear la expresión "territorio nacional", en la medida que el territorio le pertenecería intemporalmente a una comunidad de personas, identificada bajo el rótulo de "Nación" (o, a la "República", según el inciso primero del artículo 110). Tampoco es razonable pensar que el Estado, si es uno e indivisible, como los partidarios del Estado unitario reivindican, pueda realmente "dividirse" territorialmente. La división del Estado, en el lenguaje del texto constitucional anterior, parecía mejor referirse simbólicamente a la existencia de distintas unidades organizacionales cuyo ámbito de competencias estaba delimitado por un territorio determinado. Es claro que los redactores de la norma constitucional nunca tuvieron a la vista estas consideraciones y en este sentido parece una buena ventura que la norma vigente emplee en forma más apropiada la expresión "territorio nacional".

b) Conforme al nuevo texto constitucional se extienden las unidades territoriales en las cuales se divide el territorio nacional, incorporando a las provincias y comunas, aunque ya no para efectos generales -como se desprendía del antiguo artículo $3^{\circ}$ en relación con las regiones- sino para los efectos que en el nuevo inciso tercero de dicho artículo se precisan, vale decir, el deber de promover el desarrollo equitativo y solidario entre las regiones, provincias y comunas. Sin embargo, la mayor amplitud conceptual del texto anterior es aparente, ya que, para los efectos del gobierno y administración interior del Estado, antes - al igual que hoy- tenía aplicación lo dispuesto en el antiguo inciso primero del artículo 99, hoy 110: "Para el gobierno y administración interior del Estado, el territorio de la República se divide en regiones y éstas en provincias. Para los efectos de la administración local, las provincias se dividirán en comunas.". Por ende, existían restricciones constitucionales para que las divisiones territoriales de provincias y comunas tuvieran efectos adicionales.

\section{2. - Fortalecimiento de la regionalización}

Es en esta materia donde cobran mayor importancia las palabras de Saramago, pues, detrás de un aparente feliz consagración del deber de los órganos del Estado de promover el fortalecimiento de la regionalización, se encierra la pretensión de agotar el "proceso de regionalización" en la actual estructura de gobierno y administración interior del Estado.

Esta aseveración se refleja claramente en la historia de la Ley No20.050, ya que el Senado, con motivo del primer trámite constitucional del proyecto de reforma constitucional, había aprobado una redacción distinta. A este propósito, el inciso tercero del nuevo artículo $3^{\circ}$ aprobado por el Senado decía lo siguiente: "Los órganos del Estado promoverán la regionalización del país y el desarrollo equitativo entre las regiones, provincias y comunas en que se divide el territorio nacional'. Esta propuesta recogía parcialmente la Moción de los Senadores señores Chadwick, Díez, Larraín y Rome- 
$\mathrm{ro}^{12}$, que proponían agregar un nuevo inciso al artículo $3^{\circ}$ en el cual se consignara que el Estado de Chile "deberá promover la regionalización del país". La norma sancionada por el Senado sustituía la expresión "el Estado de Chile deberá" por "los órganos del Estado deberán", para explicitar la obligación que se pretendía imponer a todos los órganos del Estado.

Ahora bien y con ocasión del segundo trámite constitucional, la Comisión de Constitución, Legislación y Justicia de la Cámara de Diputados propuso sustituir el inciso tercero del artículo $3^{\circ}$ por el siguiente: "Los órganos del Estado promoverán el fortalecimiento de la regionalización del país y el desarrollo equitativo y solidario entre las regiones, provincias y comunas del territorio nacional.". La razón que tuvo a la vista la mencionada Comisión para introducir este cambio fue "la necesidad de fortalecer y no promover la regionalización del pais, por cuanto ésta ya existe" ${ }^{13}$. Sin duda que existen las regiones y que lo que se denomina regionalización es un proceso iniciado por el régimen militar a mediados de la década de los setenta del siglo pasado, orientado a perfeccionar la desconcentración de la Administración del Estado.

La idea primigenia del Senado, sin embargo, se orientaba en una dirección opuesta a la obviedad que desnudaba la referida Comisión, pues, detrás de la expresión "promoverán la regionalización del pais", se escondía el propósito de señalar un horizonte al cual deben orientarse los órganos del Estado y consignar que la institucionalidad regional existente es esencialmente provisional y en tránsito hacia una auténtica descentralización política. Esta es la razón por la cual una parte de la doctrina no hace un balance positivo de esta reforma. En este sentido, el profesor Jorge Tapia afirma lo siguiente: "A la luz de los antecedentes de texto e históricos, Las reformas producen un silenciado debilitamiento de las regiones y de la idea misma de regionalización. Aquellas son transformadas en un elemento más de la división politico-administrativa y en un mero dato de tipo electoral. La regionalización, que en esencia es un concepto técnico de orden juridicopolitico idealmente coincidente con una determinada realidad territorial, histórica $y$ antropológica cultural, resulta rechazada por una mayoría parlamentaria y por el gobierno, cuyo discurso oficial pro descentralización es desmentido en los hechos. De este modo se rechaza todo intento de elección directa de las autoridades asi como el establecimiento de elementos de autogobierno"lis.

12 Proyecto de reforma constitucional que modifica la composición y atribuciones del Congreso Nacional, la aprobación de los tratados internacionales, la integración y funciones del Tribunal Constitucional y otras materias que indica (Boletín No2.526-07). Véase en www.congreso.cl.

15 Primer Informe Complementario de la Comisión de Comisión, Legislación y Justicia de la Cámara de Diputados, de 22 de junio de 2005 . Véase en www.congreso.cl. Convendría dejar registrado, para los efectos de historia, que esta modificación fue acordada por la unanimidad de los diputados integrantes de dicha Comisión, varios de los cuales representan a distritos de regiones distintas de la Región Metropolitana. Los miembros de la Comisión son: Laura Soto González (Presidenta), señora María Pia Guzmán Mena y señores Jorge Burgos Varela, Juan Bustos Ramírez, Alberto Cardemil Herrera, Guillermo Ceroni Fuentes, Darío Paya Mira, Aníbal Pérez Lobos, Eduardo Saffirio Suárez y Gonzalo Uriarte Herrera. En reemplazo del Diputado señor Pedro Araya Guetrero asistió el Diputado señor Zarko Luksic Sandoval.

I4 Jorge TAPIA VALDÉS: "Las reformas constitucionales de 2005, un triunfo del centralismo", en Humberto Nogueira Alcalá, ob. cit., pág. 45. 
Es cierto que para avanzar en el proceso de regionalización se requeriría de una nueva reforma constitucional y que, mientras ello no acontezca, es preferible fortalecer las capacidades regionales y consolidar estrategias más exitosas de desarrollo regional. Empero, sería motivo de honda preocupación que se pretenda esgrimir la Ley No20.050 como un quiebre en el gradual y progresivo avance hacia la descentralización política.

\section{3.- Consagración expresa de los principios de equidad y solidaridad en materia de desarrollo territorial, como bases de la institucionalidad}

La consagración constitucional, entre las bases de la institucionalidad, del deber de los órganos del Estado de promover el desarrollo equitativo y solidario entre las regiones, provincias y comunas del territorio nacional, es una innovación que, sin ser estrictamente necesaria para perfeccionar nuestro ordenamiento constitucional, seguramente refleja -al menos parcialmente- la perspectiva original contenida en la Moción de los Senadores señores Chadwick, Díez, Larraín y Romero, quienes propusieron agregar un nuevo inciso al artículo $3^{\circ}$ con la siguiente redacción: "El Estado de Chile deberá promover la regionalización del país y la equidad política, económica $y$ educacional entre las regiones y comunas de Chile". Es interesante el énfasis que quisieron brindarle a la idea de "equidad" los autores de esta iniciativa, lo que motivó una ardua discusión entre los miembros de la Comisión de Constitución, Legislación, Justicia y Reglamento del Senado ${ }^{15}$. Finalmente la Comisión consideró pertinente suprimir los adjetivos de la voz "equidad" y agregar la unidad territorial "provincias" entre las cuales se divide el territorio nacional, aprobando por unanimidad la siguiente redacción: "Los órganos del Estado promoverán la regionalización del país y el desarrollo equitativo entre las regiones, provincias y comunas en que se divide el territorio nacional.".

Fue la Cámara de Diputados que brindó la configuración definitiva a este inciso, en los términos que da cuenta el Primer Informe Complementario de su Comisión de Constitución, Legislación y Justicia, la que estimó "también contemplar en el desarrollo de las regiones, provincias y comunas el factor solidaridad"16, proponiendo por unanimidad la siguiente norma: "Los órganos del Estado promoverán el fortalecimiento de la regionalización del pais y el desarrollo equitativo y solidario entre las regiones, provincias y comunas del territorio nacional.".

Decíamos que esta enmienda no era estrictamente necesaria, pero su sentido útil puede advertirse en el reforzamiento de los principios de equidad y solidaridad entre las distintas unidades territoriales y al interior de cada una de ellas. Esta última idea,

15 Los detalles se pueden consultar en el Primer Informe, en el Primer Informe Complementario y en el Segundo Informe de la Comisión de Constitución, Legislación, Justicia y Reglamento de fechas 6 de noviembre de 2001 , 8 de enero de 2002 y 18 de marzo de 2003, respectivamente, publicados en www.congreso.cl. Una sintesis de este debate se contiene también en Emilio PFEFFER URQUIAGA: "Reforma constitucionales 2005. Antecedentes - Debates - Informes" (Editorial Jurídica de Chile, Santiago de Chile, 2005).

t6. Primer Informe Complementario, de fecha 22 de junio de 2005 . Véase en www.congreso.cl. 
que se desprende de lo dispuesto en el inciso final del artículo $1^{\circ}$ de la Constitución, cuando dispone que es deber del Estado "promover la integración armónica de todos los sectores de la Nación y asegurar el derecho de las personas a participar con igualdad de oportunidades en la vida nacional', se recogía parcialmente en el inciso primero del antiguo artículo 104, hoy 115, con arreglo al cual: "Para el gobierno y administración interior del Estado a que se refiere el presente capitulo se observará como principio básico la buisqueda de un desarrollo territorial armónico y equitativo. Las leyes que se dicten al efecto deberán velar por el cumplimiento y aplicación de dicho principio, incorporando asimismo criterios de solidaridad entre las regiones, como al interior de ellas, en lo referente a la distribución de los recursos puiblicos." Asimismo, el artículo 122, ex 111, consagra igualmente el principio de solidaridad en relación con los fondos municipales: "Las municipalidades gozarán de autonomía para la administración de sus finanzas. La Ley de Presupuestos de la Nación podrá asignarles recursos para atender sus gastos, sin perjuicio de los ingresos que directamente se les confieran por la ley o se les otorguen por los gobiernos regionales respectivos. Una ley orgánica constitucional contemplará un mecanismo de redistribución solidaria de los ingresos propios entre las municipalidades del país con la denominación de fondo común municipal. Las normas de distribución de este fondo serán materia de ley." Por su parte, huelga decir que la idea de desarrollo equitativo se desprende o deriva del principio de igualdad, consagrado -entre otras disposiciones- en los artículos $1^{\circ}$ inciso primero y 19 №2 de la Carta Fundamental.

Sin perjuicio de lo anterior el fortalecimiento de estos principios y su consagración como bases de la institucionalidad sí configuran un fuerte complemento a nuestra hipótesis, cual es que estas enmiendas -en tanto perfeccionan una idea sustantiva de Estado de Derecho- tendrán un impacto en la convivencia nacional fundamentalmente en el ámbito jurisdiccional, más que en un cambio real y concreto en la conducta o decisiones espontáneas de las autoridades encargadas de diseñar, implementar, supervisar y evaluar políticas públicas.

\section{2.- Los guardianes de la Constitución}

"La vida, querido Máximo, me ha enseñado que nada es simple, que a veces lo parece, y que cuanto más lo parece, más hay que dudar." (José Saramago)"

La modificación introducida al artículo $6^{\circ}$ parece ser, a primera vista, una enmienda menor a la Carta Fundamental. Desde ya ninguna de las dos mociones que dieron origen al proyecto de reforma constitucional contiene referencia alguna a esa modificación y surge a propósito de una Indicación del Ejecutivo. Sin embargo, a no dudar, la frase que se agrega al inciso primero de este artículo, aparentemente inocente, da cuenta de uno de los temas más difíciles de abordar para la teoría constitucional. 
A partir de la Ley No20.005, a los órganos del Estado se les ha conferido el deber de "garantizar el orden institucional de la República". Es posible que esta modificación sea una transacción entre quienes deseaban suprimir la antigua oración contenida en el inciso segundo del antiguo artículo 90 de la Carta fundamental, en cuya virtud se asignaba a las Fuerzas Armadas, con exclusividad, la función de "garantizar el orden institucional de la República”, y quienes deseaban preservar este rol para las Fuerzas Armadas. Lo cierto es que, ahora entre las bases de la institucionalidad, se encomienda a todos los órganos del Estado la misión de ser guardianes de la Constitución, por cierto cada uno de ellos según su respectivo ámbito de atribuciones establecidas por el ordenamiento jurídico.

Creemos que esta enmienda en lo sustancial es muy afortunada y, probablemente sin que los redactores de la norma se lo propusieran, zanja una discusión que tiene larga data en el constitucionalismo contemporáneo en relación con quién debe ser el guardián de la Constitución. La solución que adoptó el constituyente fue rechazar la tentación intelectual y política de encomendar a un solo órgano o autoridad prevista en la Constitución, la función de ser su garante último. Este monismo jurídico-político tiene en Carl Schmitt su máxima expresión. Este autor, en su clásico libro "La defensa de la Constitución"18, defiende la tesis de que sea el Presidente del Reich el protector de la Constitución. Interesa reproducir parte de sus fundamentos y a partir de ellos preguntarnos acerca del estado de la cuestión en nuestro país. Dice Schmitt a favor de esta tesis ${ }^{19}$ que por su estabilidad y permanencia relativa (mandato por siete años, dificultad de su revocación, independencia con respecto a las cambiantes mayorías parlamentarias) y por el género de sus atribuciones (entre otras, de la facultad de disolver el Reichstag, la de promover un plebiscito, el refrendo y promulgación de las leyes), el Presidente del Reich sería una "una institución neutral que como tal sea protectora y garante del sistema constitucional y del funcionamiento adecuado de las instancias supremas del Reich, institución que además se halla dotada, para caso de necesidad, con atribuciones eficaces que le permitan realizar una defensa activa de la Constitución" ${ }^{20}$. Complementa sus fundamentos este autor indicando que el Presidente del Reich tiene que prestar juramento de "salvaguardar la Constitución". Finalmente, el argumento más relevante que plantea Schmitt es que su postura, esto es, que el Presidente del Reich sea el protector de la Constitución, "se corresponde también, ..., al principio democrático sobre el cual descansa la Constitución de Weimar" ${ }^{21}$.

Más allá de las suspicacias que este autor abriga producto de su afinidad y/o proximidad con el régimen nazi, lo cierto es que su tesis ha servido de base para la discusión

18 El texto original en alemán data del año 1931, aunque un trabajo anterior del mismo autor, denominado "El Tribunal del Reich como Guardián de la Constitución", en el cual se contienen ya sus tesis centrales, es del año 1929.

1. Carl SCHMITT: "La defensa de la Constitución" (Editorial Tecnos, S.A., Madrid, 2a edición, 1998).

20) Ob. cit., pág. 249.

2 Ob. cit., pág. 250 . 
sobre a quién le corresponde la función de preservar la Constitución. A este respecto, bajo la influencia de la doctrina de la seguridad nacional, se consagró en nuestro texto constitucional la idea de asignar la función de "garante del orden institucional de la República” a las Fuerzas Armadas. Esta solución, siempre bajo el prisma del monismo jurídico-político, ciertamente no se condice con el principio democrático que Schmitt enfatizaba, pero sí daría cuenta de parte significativa de los demás atributos, en especial por ser instituciones "permanentes" de la República y por su carácter "neutral".

El Constituyente de 2005, sin embargo, decidió salir del callejón monista y optó por la salomónica alternativa de entregar esta potestad-deber a todos los órganos del Estado, claro está, según el ámbito de sus competencias constitucionales y legales. Hoy, ninguna institución, por muy relevante que sea, puede erigirse con exclusividad en la guardiana de la Constitución. Creemos que la solución adoptada por el Constituyente es sabia, aunque nos asiste una duda enorme acerca de cuán compenetrados están nuestros órganos del Estado acerca de la significativa y delicada misión que la Constitución les confiere.

Nuestra duda e inquietud emana del comportamiento concreto por parte de órganos del Estado que, dentro del ámbito de sus atribuciones, han debido garantizar el orden institucional de la República y, a nuestro juicio, han eludido mayúsculamente dicho cometido. Para estos efectos citaré el cumplimiento que el Servicio Electoral y el Tribunal Calificador de Elecciones han brindado al requisito de residencia en la región correspondiente para ser elegido diputado o senador, conforme lo exigían los antiguos artículos 44 (hoy 48) y 46 (hoy 50) de la Carta Fundamental, respectivamente. Esa residencia debía ser por un plazo no inferior a dos años, contado hacia atrás desde el día de la elección. El sentido de la norma era muy claro: se pretendía asegurar que los candidatos a diputado o senador fueran personas con residencia en la respectiva región, de manera que no se produjera -lo que de hecho aconteció- que personas que no cumplían ese requisito se presentaran de candidatos y desplazaran a los candidatos o candidatas locales. No importa examinar si el requisito es adecuado o no. Lo cierto es que la Constitución imponía esa condición. Sin embargo, los órganos del Estado encargados en estos dominios de asegurar el pleno imperio de la Constitución aplicaron un padrón excesivamente laxo, el cual no experimentó mayores reparos por parte de los partidos políticos, toda vez que este criterio los beneficiaba por igual ${ }^{22}$. Un ejemplo de esto constituye el criterio meramente formal del Servicio

12 Una muestra del desinterés de los partidos polícicos para reclamar por el incumplimiento de este requisito constitucional podría reflejarse en el hecho de que, no obstante estar legitimados activamente para reclamar, no lo hacen y las escasas reclamaciones que se han somerido a ta consideración del TRICEL son presentadas solitariamente por los candidatos rivales. Estas últimas teclamaciones han sido generalmente declaradas inadmisibles por el TRICEL, precisamente por falta de legitimación activa para reclamar. Esto es lo que acaeció en las causas Rol № 36-2001 (reclamo interpuesto por el candidato a diputado independiente, don Iván Barbaric Sciaraffia, contra la declaración de candidatura del candidato a senador don Fernando Flores Labra) y No85-2005 (reclamo interpuesto por el postulante a diputado don Waldo Mora Longa impugnando la resolución del Servicio Electoral que aceptó la declaración de candidatura a diputado de don Felipe Ward Edwards). En este último caso, según se corrobora en los Vistos de la Sentencia de fecha 7 de octubre de 2005, el Partido UDI sostenia que el candidato 
Electoral, confirmado por el Tribunal Calificador de Elecciones ${ }^{23}$, de dar por cumplido con este requisito mediante la presentación de una declaración jurada ante Notario Público en la cual el o la candidato/a declaraba tener residencia en la región.

Habida cuenta de esta actitud tan complaciente y poco rigurosa no es de extrañar que el Constituyente haya optado por suprimir el requisito de residencia para ser elegido senador, conforme la nueva redacción del artículo 50 de la Carta Fundamental.

Una situación más escandalosa es el uso y abuso por parte de la Corte Suprema de la potestad para disponer el traslado de los jueces, medida que generalmente se asocia a una sanción disciplinaria, la cual es empleada difusamente para nombrar como $\mathrm{Mi}$ nistros de Corte de Apelaciones a personas que, no invistiendo la calidad de "jueces", se desempeñan como Relatores ante la Corte Suprema, es decir, a personas que revisten la dignidad de "auxiliares de la Administración de Justicia". Esta práctica contraría groseramente lo dispuesto en el artículo 78 de la Constitución, ex 75, en cuya virtud "Los ministros y fiscales judiciales de las Cortes de Apelaciones serán designados por el Presidente de la República, a propuesta en terna de la Corte Suprema". No interesa abundar en esta ocasión en torno a esta anomalía, mas sí consignar que la ciudadanía, y no sólo la academia, espera una actitud distinta para dar fiel y leal aplicación a las normas constitucionales, especialmente por parte de los tribunales.

Es frente a estas y muchísimas otras transgresiones a la Constitución que nos permitimos preguntarnos si los órganos del Estado están preparados, especialmente desde una perspectiva cultural, para satisfacer la enorme y trascendente responsabilidad que el Constituyente ha depositado en ellos. Los hechos descritos llaman a dudar.

En este estadio convendría quizás plantearse acerca de la conveniencia de instaurar una acción popular para cautelar que los órganos del Estado realmente desempeñen la atribución que se les ha encomendado. En nuestra historia constitucional encontramos un precedente para esta propuesta. Nos referimos a las disposiciones contenidas en el Título IX de la Constitución de $1822^{24}$ ("De la observancia de la Constitución y su publicación"), cuyo artículo 243 disponía lo siguiente: "Todo chileno tiene derecho

cumplía con el requisito de residencia, para lo cual acredita que éste era socio de una sociedad que celebró un contrato con una empresa de la zona y contratos de subarriendo de oficinas en una ciudad de la región. Es evidente que estos antecedentes no configuran el requisito de "residencia", pues a lo sumo constituyen un "domicilio".

13 El Tribunal Calificador de Elecciones, en causa Rol No83-2005, mediante sentencia de fecha 6 de octubre de 2005, acogió el reclamo de don Minor Braniff Mera contra la resolución del Servicio Electoral que rechazó su declaración de candidarura independiente. entre ocros reproches, por no acompañar declatación jurada para probar el requisito de residencia en la región respectiva. El reclamante, para fundar su reclamo, acompañó una declaración jurada ante Notario Público y el Tribunal Calificador de Elecciones declara que "los documentos referidos resultan suficientes para comprobar que el reclamante cumple y cumplia con los requisitos establecidos por el vigente articulo 48 (44) de la Constitución Politica de la República, por lo que su declaración de candidatura debe ser aceptada" (Considerando 30).

24 Véase en Luis VALENCLA AVARIA: "Anales de la República" (Editorial Andrés Bello, Santiago de Chile, 2a edición, 1986). 
a pedir la observancia de la Constitución, y a que se castigue al infractor de ella, sea cual fuere su clase o investidura"25. Esta norma nos parece ejemplarmente republicana y convendría tenerla a la vista en una próxima revisión constitucional, como asimismo el artículo 247 de dicha Carta Fundamental que imponía un deber genérico a todas las autoridades públicas de jurar la observancia de la Constitución.

En suma, la solución que encontraron los redactores de la nueva norma constitucional a la pregunta de quién debe ser el "protector" de la Constitución fue simple y salomónica; empero, parafraseando a Saramago, nos parece que por su simpleza nos llama a duda. Esperamos que con el tiempo opere una favorable compenetración de los órganos del Estado con esta nueva potestad-deber, adecuando la cultura jurídica corporativa si fuere necesario, sin perjuicio de incorporar a la Constitución una acción popular que permita un diligente control ciudadano en caso de inobservancia de la Carta Fundamental, máxime si el "defensor" o "protector" último de la Constitución, a nuestro juicio, deberíamos ser los ciudadanos y no los órganos del Estado, y menos uno de éstos en particular.

\section{3.- Principios de Probidad, Transparencia y Publicidad y Deber de Fundamentación}

"Al contrario de lo que generalmente se piensa, tomar una decisión es una de las decisiones más fáciles de este mundo, como cabalmente se demuestra con el hecho de que no hacemos nada más que multiplicarlas a lo largo del santisimo dia, aunque, y ahi tropezamos con el busilis de la cuestión, éstas siempre nos traen a posteriori sus problemitas particulares, o, para que nos entendamos, sus rabos asomando, siendo el primero nuestro grado para mantenerlas y el segundo nuestro grado de voluntad para realizarlas." (José Saramago) ${ }^{26}$

Las palabras de Saramago parecen proféticas. Prácticamente nos indican que, habiendo entrado en vigencia los nuevos principios y deberes del artículo $8^{\circ}$, el desafío verdadero consiste en tomárselos en serio, pues esta es, entre las modificaciones al Capítulo I que estamos comentando, la que goza de mayor impacto directo e inmediato, obligando a los órganos del Estado a obrar de una manera distinta e iniciar una nueva relación con la ciudadanía. Habrá que apreciar, entonces, la voluntad real de los agentes públicos para realizar el propósito de las enmiendas.

La decisión del Constituyente de sancionar un nuevo artículo $8^{\circ}$, cuyo contenido había quedado en blanco merced al pacto social del año 1989, es correcta. También lo es que se incorporen como bases de la institucionalidad una serie de principios que se encon-

:5 Los redactores de esta Constitución tuvieron a la vista, seguramente, el Título X de la Constitución de Cádiz, de 1812, el cual versaba acerca "De la observancia de la Constitución y modo de proceder para hacer variaciones en ella", en cuyo artículo 373 se prescribia que "todo español tiene derecho a representar a las Cortes o al Rey para reclamar la observancia de la Constitución". Véase en Jorge DE ESTEBAN: "Las Constituciones de España" (Centro de Estudios Políticos y Constitucionales, Madrid, 1998).

26. José SARAMAGO: Ob. cit., pág. 348. 
traban consagrados en distintas normas jurídicas y que son muy relevantes para el Derecho Público. La duda que persiste es cuál será la evolución, tanto de los órganos del Estado que deben aplicarlos y, asimismo, el rigor con que la jurisprudencia administrativa y jurisdiccional los promuevan y/o apliquen. También debe estar bajo nuestra atenta vigilancia la conducta de estos órganos fiscalizadores, especialmente la Contraloría General de la República, el Tribunal Constitucional y el Poder Judicial, los cuales también deben adecuar su funcionamiento a estos nuevos principios y deberes.

\section{1.- Consagración constitucional del principio de probidad}

El Constituyente establece como nuevo inciso primero del artículo $8^{\circ}$ la siguiente norma: "El ejercicio de las funciones públicas obliga a sus titulares a dar estricto cumplimiento al principio de probidad en todas sus actuaciones."

Esta norma plantea las interrogantes de qué debe entenderse por "función pública" y en qué consiste el "principio de probidad".

¿Qué se entiende por "función pública"?

En lo que atañe a la "función pública" existe una duda razonable de si comprende a los "empleados públicos", sea que se rijan por la Ley Orgánica Constitucional sobre Bases Generales de la Administración del Estado, a que alude el artículo 38 de la Constitución, u otra normativa especial, o, en una interpretación más amplia, si se refiere también a las demás personas que, aun cuando no posean la calidad de empleado público, sirven una determinada función pública. Estas perspectivas se tuvieron a la vista durante la deliberación parlamentaria y, al tenor del texto finalmente aprobado, no consideramos que en esa historia se dé cuenta de un antecedente definitivo que permita dirimir la cuestión y la materia está entregada a la interpretación autorizada de la jurisprudencia administrativa y judicial.

Nuestra postura en la materia es que la exigencia del principio de probidad se extienda hasta donde el interés público razonablemente exija que sea exigible dicho principio. Empero, de la norma constitucional emanarían algunas restricciones al ámbito de aplicación imperativa de este principio, derivadas del empleo de la expresión: "El ejercicio de la funciones públicas obliga a sus titulares...".

En este sentido:

a) La idea de "función pública" o, en plural "funciones públicas", en la medida que se asimile a la noción de "empleo público" ${ }^{27}$ podría importar una restricción significativa. Es cierto que a veces algunas normas jurídicas emplean estas expresiones aparentemente en forma sinónima, entre ellas el artículo $19 \mathrm{~N}^{\circ} 17$

En parte esta confusión terminológica se debe a la jurisprudencia administrativa, la que en no pocas ocasiones tiende a asimilar las nociones de función pública y empleo o cargo público. Por ejemplo, véanse los Dictámenes de la Contraloria General de la República Nos. 26.560 y 38.583, ambos de 2005. 
de la Constitución; pero es claro que se trata de dos conceptos diferentes y que el constituyente también así lo ha entendido, por ejemplo, en la norma contenida en el inciso cuarto $\mathrm{N}^{\circ} 2$ del artículo 65: "Corresponderá, asimismo, al Presidente de la República la iniciativa exclusiva para: (...) $2^{\circ}$.- Crear nuevos servicios públicos o empleos rentados, sean fiscales, semifiscales, autónomos o de las empresas del Estado; suprimirlos y determinar sus funciones o atribuciones; ...". Por consiguiente, no creemos que la voz "funciones públicas" se restrinja a la idea de "empleos públicos", cuya fuente de renta sea o no con cargo al presupuesto estatal, como tampoco que las "funciones públicas" aludidas en el artículo $8^{\circ}$ de la Constitución se limite a aquellas que son servidas por personas que posean una relación contractual de dependencia con algún órgano del Estado.

b) La limitación que los servidores o funcionarios desempeñen tal función en calidad de "titulares", es decir, que, conforme a lo dispuesto en el inciso primero del artículo $7^{\circ}$ de la Constitución, estén "investidos regularmente" de tal condición. No nos referimos a que los funcionarios, siguiendo la nomenclatura del artículo $4^{\circ}$ del Estatuto Administrativo ${ }^{28}$, sirvan su función en calidad de "titulares", en contraposición a la de "suplentes" o "subrogantes". La idea de citularidad que creemos es exigible, según la norma constitucional en estudio, mira a si quien desempeña esta función lo hace mediante elección, nombramiento, designación o cualesquier otro mecanismo expresamente previsto en la Constitución o en las leyes para desempeñar una función pública, de suerte que tal desempeño deba seguir prestándose en tanto no concurra una causal de cesación expresamente prevista en la Constitución o en las leyes. Esta interpretación guarda también vinculación con lo prescrito en el artículo $19 \mathrm{~N}^{\circ} 17$, en cuya virtud la Constitución asegura a todas las personas "la admisión a todas las funciones o empleos públicos, sin otros requisitos que los que impongan la Constitución o las leyes".

c) Una situación más discutible es si procede o no que una persona contratada bajo la modalidad de honorarios pueda cumplir una función pública. La Contraloría General de la República ha observado una interpretación fluctuante que no arroja luces definitivas sobre el problema. Así, recientemente ha señalado que las normas sobre probidad administrativa "deben ser observadas por todos quienes ejercen una función pública, cualquiera sea su naturaleza o jerarquia, no distinguiendo el legislador sobre las calidades en que se sirven los empleos"29 , haciendo aplicable expresamente este criterio a los profesionales contratados a honorarios. Con antelación a ese dictamen la Contraloría ya había

3. Ley $\mathrm{N}^{\circ} 18.834$, cuyo texto refundido, coordinado y sistematizado fue fijado mediante el DFL N²9, de 2004, del Ministerio de Hacienda, publicado en el Diario Oficial con fecha 16 de marzo de 2005.

29 Dictamen $\mathrm{N}^{\circ} 11.023$, de 9 de marzo de 2006. 
aseverado que las personas contratadas a honorarios "deben observar el principio de probidad administrativa por tener el carácter de servidores estatales" ${ }^{30}$. Empero, la Contraloría el año pasado ${ }^{31}$ había sentado exactamente el criterio opuesto, incluso reconsiderando dictámenes anteriores y toda jurisprudencia en contrario, aseverando que personal a honorarios no puede desempeñar funciones públicas, las que sólo pueden ser servidas por personas que ocupen cargos de planta o a contrata. Es posible que este cambio de criterio responda a la entrada en vigencia de la nueva norma constitucional. En todo caso, nuestro criterio es concordante con la idea de que personas contratadas bajo la modalidad de honorarios pueden desempeñar una función pública y están afectos al principio de probidad, sin perjuicio de la conveniencia de restringir el cumplimiento de funciones directivas al personal que sirve bajo una modalidad contractual más estable y afecto a un régimen más estricto de responsabilidad.

ch) La duda más relevante podría plantearse respecto de quien desempeña una función pública mediante el mecanismo de la licitación pública, licitación privada, convenio de colaboración, convenio mandato u otro mecanismo de adjudicación o concesión de servicio. En este punto parece interesante recopilar que la Contraloría General de la República, entre otras situaciones, ha indicado que los servicios que presta una corporación municipal de educación, salud y atención al menor importan el desempeño de una función pública $^{32}$, que las actividades de extracción, transporte y disposición de los residuos sólidos domiciliarios constituyen el ejercicio de una función pública, sea que se presten directamente por las municipalidades o por un tercero titular de una concesión de servicio ${ }^{33}$ y que un Director de escuela dependiente de un municipio desarrolla actuaciones propias de su función pública ${ }^{34}$. También, el organismo contralor, ha sentado que los integrantes de diversas entidades públicas, entre ellas una empresa estatal - CODELCO ${ }^{35}$ - y una comisión asesora -la Comisión Nacional de Iniciativas Científicas para el Milenio ${ }^{36}$-, han de dar cumplimiento al principio de probidad. Igualmente, la Contraloría he entendido la sujeción a este principio constitucional a funcionarios públicos en actuaciones que no son propias del cargo o función, como es el caso de los funcionarios municipales o concejales que integran juntas de vecinos ${ }^{37}$. Esta jurisprudencia nos permite aventurar que existe una comprensión am-

\footnotetext{
Dictamen $\mathrm{N}^{\circ} 372$, de 2006.

Dictamen $N^{\circ} 27.050$, de 8 de junio de 2005.

Dictamen $\mathrm{N}^{\circ} 7.935$, de 2006.

Dictamen No15.606, de 2005.

Dictamen $\mathrm{N}^{\circ} 22.233$, de 2006.

Dictamen $\mathrm{N}^{\circ} 12.131$, de 2006.

Dictamen $N^{\circ} 46.020$, de 2005.

Dictamen N³.817, de 2006.
} 
plia de la idea de función pública y que resulta razonable extender esta noción a todas aquellas funciones que el ordenamiento jurídico encomienda a un órgano del Estado, independientemente de si esta potestad-deber es cumplida directamente por éste o por un tercero mediante una modalidad contractual autorizada por el ordenamiento jurídico vigente.

¿Qué se entiende por "principio de probidad"?

La Constitución no define qué debe entenderse por "principio de probidad" y corresponde al intérprete definir su sentido y alcance.

Para estos efectos es útil comenzar haciendo una revista a diversas definiciones lingüísticas o doctrinarias. Así, la Real Academia Española emplea esta voz como sinónimo de "honradez" ${ }^{38}$ y Guillermo Cabanellas agrega la noción de "rectitud de ánimo y del proceder" ${ }^{39}$.

También a modo referencial ${ }^{40}$ debemos tener a la vista la definición contenida en el artículo 52 de la Ley $\mathrm{N}^{\circ} 18.575$, Orgánica Constitucional sobre Bases Generales de la Administración del Estado, en cuya virtud el principio de probidad administrativa "consiste en observar una conducta funcionaria intachable y un desempeño honesto y leal de la función pública o cargo, con preeminencia del interés general sobre el particular" ${ }^{\prime 1}$. Aparece evidente en esta definición legal una noción "compuesta" de probidad, en la medida que se precisan diversas conductas, la primera de las cuales ("observar una conducta funcionaria intachable") reitera en gran medida las definiciones de la Real Academia Española y la brindada por Cabanellas. La segunda parte de la definición legal, especialmente en lo relativo a la preeminencia del interés general sobre el particular, es corolario de una insistente jurisprudencia administrativa previa y dota a esa definición de una interesante riqueza conceptual.

Sin embargo, la ley Orgánica Constitucional, en su artículo 53, ensancha considerablemente el concepto de "probidad administrativa" al especificar qué se entiende por "interés general": "El interés general exige el empleo de medios idóneos de diagnóstico, decisión y control, para concretar, dentro del orden juridico, una gestión eficiente y eficaz. Se expresa en el recto y correcto ejercicio del poder público por parte de las autoridades adminis-

3. Real Academia Española: "Diccionario de la Lenguta Española" (Editorial Espasa Calpe, S.A., Madrid, 22a edición, 2001, Tomo II, pág. 1.837).

39. Guillermo CABANELLAS: "Diccionario de derecho usual" (Bibliográfica Ameba, Buenos Aires, 6a edición, 1968, Tomo IIl, pág. 389).

4" No obstante tratarse de una definición legal, no corresponde otorgarle la autoridad que prescribe el artículo 20 del Código Civil, toda vez que una norma legal no puede precisar el sentido y alcance de una norma constitucional, primero por razones de jerarquia normativa 0 , mejor dicho, por un asunto de distribución de competencias y, por el otro lado, porque la facultad de dirimir su sentido y alcance es una atribución exclusiva y excluyente de los órganos competentes y, en particular, de los tribunales que señale la ley, en virtud de lo dispuesto en el inciso primero del artículo 76 de la Constitución. Naturalmente la definición legal es vinculante para interpretar la sujeción a este principio cuando ello deriva de un mandato meramente legal, no constitucional.

41 Esta definición deriva de lo prescrito en el inciso segundo del articulo 52, el cual a su vez se contiene en el Título III ("De la probidad administrativa") de la referida ley. 
trativas; en lo razonable e imparcial de sus decisiones; en la rectitud de ejecución de las normas, planes, programas y acciones; en la integridad ética y profesional de la administración de los recursos públicos que se gestionan; en la expedición en el cumplimiento de sus funciones legales, y en el acceso ciudadano a la información administrativa, en conformidad a la ley." Esta última disposición debe entenderse en relación con las sanciones previstas por infracción al principio de probidad y, en particular, con el artículo 62 de la misma ley, que enuncia diversas conductas, entre ellas, "contravenir los deberes de eficiencia, eficacia y legalidad que rigen el desempeño de los cargos públicos, con grave entorpecimiento del servicio o del ejercicio de los derechos ciudadanos ante la Administración" $\left(\mathrm{N}^{\circ} 8\right)$.

Habida cuenta del inmensurable dominio del principio de probidad en el desempeño de la función pública, según la Ley Orgánica Constitucional aludida, no es de extrañar que la Contraloría extienda la aplicación de este principio a múltiples conductas, no todas las cuales dicen estricta relación con una rectitud de voluntad en el desempeño de la función pública, invadiendo otros ámbitos del comportamiento humano. Así, la jurisprudencia administrativa ha afirmado que importan contravenciones a este principio, entre otras, las siguientes conductas: un abuso sexual o, en su caso, una hipótesis de acoso sexual ${ }^{42}$, permitir el uso ilegal de la conexión de televisión de cable ${ }^{43}$; participar en decisiones en que exista cualquier circunstancia que reste imparcialidad ${ }^{44}$; el funcionario de la Policía de Investigaciones que solicita permiso para que una mujer que goza de reclusión nocturna y con la cual mantiene una relación de amistad, llegue más allá de la hora debida al recinto penitenciario ${ }^{45}$, etc. Evidentemente todas estas conductas nos parecen reprochables, pero es dable preguntarse cuál es el límite conceptual de este principio o, dicho de otra manera, qué conductas jurídicamente reprochables de un funcionario constituyen infracciones específicas al principio de probidad.

Es más, la exigencia del principio de probidad en la jurisprudencia de la Contraloría se aplica incluso a situaciones de riesgo o peligro, aunque no importen la realización actual de una conducta reprochable, de suerte que se debe "evitar, aunque sólo sea potencialmente, que las prerrogativas o esferas de influencia del funcionario público incidan $o$ se relacionen con las labores propias de la institución o sean propias del departamento o unidad donde se desempeña" ${ }^{46}$.

42 Dictamen $N^{036.814, ~ d e ~ 2005 . ~ A q u i ́ ~ l a ~ c o n d u c t a ~ e s p e c i f i c a ~ h a b r i ́ a ~ c o n s i s t i d o ~ e n ~ t o m a r ~ p o r ~ l a ~ c i n t u r a ~ y ~ a t r a e r ~}$ hacia su cuerpo a funcionaria sin su consentimiento.

43 Dictamen $\mathrm{N}^{\circ} 60.497$, de 2005.

4 Dictamen $\mathrm{N}^{\circ} 12.305$, de 2006.

4 Dictamen $\mathrm{N}^{\circ} 50.704$, de 2005.

4 Dictamen $\mathrm{N}^{\circ} 59.921$, de 2005. 
No está en discusión la pertinencia de aplicar las normas de la Ley Orgánica Constitucional a los funcionarios cuyas normas les son aplicables; pero creemos que debe darse al ahora principio constitucional de probidad una extensión más razonable, sin pretender abarcar y agotar bajo su imperio el ideal ético. A este respecto, sigue fresca en la memoria la denominada Constitución "moralista" de 1823, propiciada por don Juan Egaña, que tuvo breve y exigua aplicación.

\section{2.- Consagración constitucional de los principios de transparencia y publicidad}

En lo tocante al nuevo inciso segundo del artículo $8^{\circ}$, el Constituyente estableció la siguiente norma: "Son públicos los actos y resoluciones de los órganos del Estado, así como sus fundamentos y los procedimientos que utilicen. Sin embargo, sólo una ley de quórum calificado podrá establecer la reserva o secreto de aquéllos o de éstos, cuando la publicidad afectare el debido cumplimiento de las funciones de dichos órganos, Los derechos de las personas, la seguridad de la Nación o el interés nacional".

Al respecto, tres son los aspectos o consecuencias más interesantes de la citada disposición:

1. El primero, tiene que ver con el objeto mismo sobre el cual recae el principio de publicidad, constituyendo este objeto todos los "actos y resoluciones de los órganos del Estado", así como sus "fundamentos" y los "procedimientos" utilizados para llegar a dichos actos y resoluciones. En este punto es útil puntualizar que la jurisprudencia administrativa ${ }^{47}$ distingue, en base a lo prescrito en el artículo 13 de la Ley Orgánica Constitucional sobre Bases Generales de la Administración del Estado, entre el "principio de transparencia" aplicable a la función pública y el principio de "publicidad". En relación con el primer principio, el inciso segundo de dicho artículo dispone lo siguiente: "La función pública se ejercerá con transparencia, de manera que permita y promueva el conocimiento de los procedimientos, contenidos y fundamentos de las decisiones que se adopten en el ejercicio de ella"; mientras que, respecto del principio de publicidad, el inciso tercero preceptúa que "son públicos los actos administrativos de los órganos de la Administración del Estado y los documentos que les sirvan de sustento o complemento directo y esencial'.

De lo anterior, se desprende que en el ámbito administrativo se amplía el espectro de los actos que deben ser objeto del principio de publicidad, ya que con anterioridad a la entrada en vigencia de la reforma constitucional, eran públicos sólo los "actos administrativos" de los órganos de la Administración del Estado y los "documentos que les sirvieran de sustento o complemento directo o

4" Ver, a modo de ejemplo, los Dictámenes de la Contraloría General de la República Ns. 46.589 y 60.313. ambos de 2005 , y $9.082,10.435$ y 23.473. los tres de 2006 . 
esencial", entendiendo la expresión "acto administrativo" en el sentido que le otorgara el artículo $3^{\circ}$ de la Ley $\mathrm{N}^{\circ} 19.880$, que establece bases de los procedimientos administrativos que rigen los actos de los órganos de la Administración del Estado ${ }^{48}$, esto es, de decisiones formales que emiten los órganos de la Administración en las cuales se contienen declaraciones de voluntad realizadas en el ejercicio de una potestad pública. De ahora en adelante, cualquier "acto o resolución" que emitan los órganos del Estado se encontrará afecto al principio de la publicidad, ya no sólo las decisiones formales y escritas de voluntad de los órganos de la Administración del Estado, así como también son públicos los "fundamentos" de dichos actos y resoluciones, aun cuando no se trate de documentos que sirven al acto administrativo de sustento o complemento directo y esencial. En cierta forma, eso sí, la Contraloría entendía que la contravención al principio de transparencia se sancionaba ${ }^{49}$ como una infracción al principio de probidad, al tenor de lo previsto en el artículo 53 de la LOC, ya citado; aunque en otros dictámenes el organismo contralor distingue entre los principios de probidad y transparencia ${ }^{50}$.

Ciertamente el principio de transparencia, antes de la reforma constitucional, no se concebía sólo como un principio de derecho administrativo pues también tenía (y tiene) aplicación en otro dominios, por ejemplo lo dispuesto en la Ley $\mathrm{N}^{\circ} 19.884$, sobre transparencia, límite y control del gasto electoral o la Ley $N^{\circ} 19.863$, en materia de transparencia presupuestaria. Con todo, con la reforma constitucional se ha visto fortalecida la tesis de que la actuación de los órganos del Estado y el desempeño de toda función pública debe hacerse con arreglo a estos dos principios, los cuales a no dudar están íntimamente vinculados.

2. El segundo aspecto a destacar de la norma se refiere a que el nuevo artículo $8^{\circ}$ implica una prohibición constitucional a la declaración de secreto o reserva por vía reglamentaria, a raíz de lo cual en el ámbito administrativo quedó tácitamente derogado el Reglamento sobre Secreto o Reserva de los Actos y Documentos de la Administración del Estado, aprobado por Decreto Supremo $N^{\circ} 26$, de 2001, del Ministerio Secretaría General de la Presidencia, derogación que fue expresamente declarada con posterioridad, mediante el Decreto Supremo $\mathrm{N}^{\circ} 134$, de 2005 , del mismo Ministerio, todo ello para una mayor certeza jurídica. Por su parte, la Contraloría estimó que los reglamentos internos de cada servicio, con el advenimiento de la nueva norma constitucional, quedaron "sin sustento jurídico, resultando, además, inconciliable con la nueva preceptiva de la Constitución" $"$.

4s Publicada en el Diario Oficial con fecha 29 de mayo de 2003.

4. La Contraloria entiende que la infracción al deber de desempeñar la función pública con transparencia importa una infracción al principio de probidad. Ver Dictamen $\mathrm{N}^{\circ} 16.342$, de 2006.

5.1. Ver Dictámenes $\mathrm{N}^{\circ} \mathrm{s}$. 38.150 y 47.128, ambos de 2005.

3 Dictamen N 5.232 , de 2006. Ver también Dictamen $N^{\circ} 43.809$, de 2005. 
A consecuencia de lo anterior, se encuentran derogadas tácitamente todas las resoluciones que dictaron los órganos de la Administración del Estado, en virtud de las cuales se declaró secretos o reservados determinados actos y documentos en poder de la Administración, emitidas al amparo de lo dispuesto en el inciso final del artículo 13 de la Ley Orgánica Constitucional sobre Bases Generales de la Administración del Estado y de lo dispuesto en el citado Reglamento, en cuya virtud los jefes superiores de servicio estaban habilitados para determinar, por resolución fundada, los actos, documentos $\mathrm{y}$ antecedentes internos de la institución que estarian afectos al secreto $o$ reserva, de acuerdo a los criterios fijados en el mismo Reglamento.

3. El tercer aspecto interesante de la norma y quizá más sensible radica en determinar qué pasará con los actos y resoluciones de los órganos del Estado cuya publicidad pudiera afectar el debido cumplimiento de las funciones de dichos órganos, los derechos de las personas, la seguridad de la Nación o el interés nacional, mientras no se dicte la ley de quórum calificado que establecerá el secreto o reserva de aquéllos.

En este sentido, es claro que al momento de dictarse dicha ley sabremos con certeza qué actos y resoluciones de los órganos del Estado harán excepción al principio de la publicidad, al establecerse su secreto o reserva, según corresponda. Sin embargo, en el intertanto existirán múltiples casos en que se solicitará a un organismo público el acceso a un determinado acto o documento, o su correspondiente fundamentación. En este caso surgirá para la respectiva repartición pública la disyuntiva de acceder a la petición de publicidad del acto, basada en el hecho de que mientras no se dicte la ley de quórum calificado rige en plenitud y sin limitaciones el principio de la publicidad, o bien, negarse a la publicidad del acto o antecedente solicitado, cuando de manera justificada, afectare el debido cumplimiento de las funciones de dichos órganos, los derechos de las personas, la seguridad de la Nación o el interés nacional, incluso en ausencia de una ley de quórum calificado que así lo declare.

Creemos que esta segunda opción es la válida, ya que de optar por la primera solución podría llevar a la indefensión tanto de los terceros que pueden verse válidamente afectados con la publicidad del acto o documento, o que se produzca el efecto no deseado de entorpecer el debido cumplimiento de las funciones del órgano del Estado requerido $\mathrm{o}$, incluso, se afecten concretamente la seguridad y el interés nacional. Estimamos que el jefe superior del órgano requerido no podría desproteger estos derechos o intereses y que razonablemente está en la obligación de apreciar las circunstancias del caso y de juzgar razonablemente las circunstancias de cada caso. En nuestra opinión, la norma constitucional es equilibrada y no puede esgrimirse que en ausencia de una ley de quórum calificado, falencia que podría ser relativamente prolongada, el constituyente haya deseado que tales derechos e intereses queden desprotegidos. 
En esta disyuntiva la Contraloría General de la República, aparentemente, se está inclinando por el criterio enunciado precedentemente, exigiendo en su caso que la negativa se realice "fundadamente y por escrito" 52 , aunque también ha sostenido el criterio contrario, esto es, que la exigencia de publicidad es absoluta hasta en tanto no se apruebe la respectiva ley de quórum calificado ${ }^{53}$.

Considerando entonces que, en el ámbito administrativo, el artículo $13^{\circ}$ del D.F.L. $N^{\circ} 1 / 19.653$, de 2000 -que aprobó el texto refundido, coordinado y sistematizado de la Ley Orgánica Constitucional de Bases Generales de Administración del Estado-, estableció las causales por las cuales el jefe superior del órgano requerido se encontraba facultado para denegar el acceso a la documentación solicitada; que no existe contradicción material entre las causales que permiten declarar el secreto o reserva establecidas en el citado artículo $13^{\circ}$ y las establecidas en el nuevo artículo $8^{\circ}$ de la Constitución, a excepción hecha de la declaración de secreto o reserva establecidos en disposiciones reglamentarias; y considerando también que dicho artículo se encuentra recogido en una ley de carácter orgánico constitucional, podemos seńalar que con la entrada en vigencia del nuevo precepto constitucional, la regulación del derecho al acceso a la información administrativa contenida actualmente en los artículos $13^{\circ} \mathrm{y}$ $14^{\circ}$ del D.F.L. $N^{\circ} 1 / 19.653$, de 2000 , es plenamente aplicable en la actualidad a la actividad de los órganos de la Administración en todo aquello que no sea contrario al nuevo precepto constitucional, es decir, las causales establecidas en el citado artículo $13^{\circ}$ que autorizan al jefe del órgano a denegar la entrega de la información se encuentran plenamente vigentes, a excepción de las causales que van claramente en contra del nuevo artículo $8^{\circ}$, es decir, los casos de secreto o reserva establecidos en disposiciones reglamentarias, por lo cual el jefe de servicio ya no podrá invocar como fundamento para denegar la entrega de información administrativa el Reglamento sobre Secreto o Reserva de los Actos y Documentos de la Administración del Estado aprobado por Decreto Supremo $N^{\circ} 26$, de 2001, del Ministerio Secretaría General de la Presidencia- ni las resoluciones que cada servicio dictó al amparo del citado Reglamento que declaraban el secreto o reserva de ciertos antecedentes.

De esta manera, mientras no se dicte la referida ley de quórum calificado, los órganos del Estado podrán continuar aplicando la regulación que en materia de acceso a la información administrativa efectúa la Ley Orgánica Constitucional de Bases Generales de Administración del Estado, para lo cual se deberá determinar de manera justificada y debidamente fundamentada, caso a caso, si la publicidad del documento solicitado pudiera afectar el debido cumplimiento de las funciones de dichos órganos, los derechos de las personas, la seguridad de la Nación o el interés nacional.

$\because \quad$ Dictamen $\mathrm{N}^{\circ} 2.607$, de 2006. El mismo criterio se infiere de los Dictámenes $\mathrm{N}^{\circ} \mathrm{s} 11.362$, de 2006 y 60.313 , de 2005. En ambos casos la Contraloría desestima la justificación del secreto o reserva esgrimida por el organismo respectivo, pero no afirma que no pueda esgrimirse directamente una causal constitucional en ausencia de ley de quórum calificado que establezca el secreco o reserva.

3 Dictámenes $\mathrm{N}^{\circ} 49.022$ y 54.138 , ambos de 2005. 
Con todo, estimamos que la reforma constitucional está llamada a suscitar un profundo impacto en la convivencia nacional. Dicho impacto pende de la ley aprobada con quórum calificado que, por razones de seguridad jurídica, deberá precisar específicamente el ámbito autorizado para el secreto o la reserva. Esperamos que el legislador no restrinja o minimice el perfeccionamiento de nuestro Estado Democrático y Constitucional de Derecho que ha procurado razonablemente la Ley de Reforma Constitucional última. También creemos que, para fortalecer nuestro sistema de controles y contrapesos y para suprimir efectivamente los "arcana imperii" y la mentira factual, conveniente sería establecer un Defensor del Pueblo en los términos que sugerimos en un artículo anterior ${ }^{54}$.

\section{3.- Consagración en las Bases de la Institucionalidad del deber de fundar los actos o resoluciones ("principio de motivación")}

La nueva norma constitucional, ya reproducida, dispone que son públicos, entre otros asuntos, los "fundamentos" de los actos o resoluciones de los órganos del Estado. De ello se colige que tales actos o resoluciones deben ser fundados, es decir, que los fundamentos que justifican su expedición estén asequibles al público. Adicionalmente entendemos que tales fundamentos deben constar en el mismo acto o resolución. Merced a esta norma constitucional se generaliza a todos los órganos del Estado la norma constitucional prevista, específicamente, para los "órganos que ejercen jurisdicción" contenida en el artículo $19 \mathrm{~N}^{\circ} 3$ inciso quinto, primera parte, a saber: "Toda sentencia de un órgano que ejerza jurisdicción debe fundarse en un proceso previo legalmente tramitado".

El reforzamiento de esta obligación de fundar los "actos y resoluciones" es, a no dudar, una de las enmiendas más significativas para el fortalecimiento del Estado Democrático y Constitucional de Derecho en nuestro país. Es más, esta modificación representa un triunfo para quienes creemos que los derechos fundamentales se realizan virtuosamente en el espacio público, no en la privacidad, puesto que este espacio público, ahora regido conforme a los cánones del principio de razonabilidad, tan relevante para el Estado Democrático y Constitucional de Derecho, deja de ser el reino de la arbitrariedad y el abuso. El nuevo inciso segundo del artículo $8^{\circ}$ de la Constitución, en lo relativo a la obligación de fundar actos y resoluciones, justifica por sí mismo la enorme complacencia que, desde la academia, brindamos a esta reforma constitucional.

Para entender su profundo significado convendría repasar el estado del arte, en el orden administrativo, con antelación a la reforma constitucional. En este punto, la

54 Véase Augusto QUINTANA BENAVIDES: "El establecimiento del Ombudsman como el gran supervisor del sistema de tutela de derechos", en Revista de Derecho Público, Universidad de Chile, Vol. 67, 2005, págs. 267 y sgtes. 
Contraloría, en algunas hipótesis establecidas en la ley ${ }^{55}$, exigía la expedición de una "resolución fundada", entendiendo por ésta "si las consideraciones, razones o circunstancias son de carácter objetivo, atingentes a la situación investigada, acorde al mérito del proceso y ajustadas a la legalidad" ${ }^{56}$, o bien cuando "existe correspondencia entre los argumentos esgrimidos para modificar la medida propuesta y la magnitud de la modificación, es decir a mayor alteración de la sanción, los fundamentos invocados deben ser de mayor importancia" $^{\text {57. }}$.

Adicionalmente, la Contraloría reconocía la vigencia del denominado "principio de motivación", en cuya virtud "la administración se encuentra en el deber de fundamentar las decisiones que adopte en el ejercicio de sus potestades, sean éstas regladas o discrecionales, lo cual es sin desmedro, además, de la posibilidad que siempre tendrán los administrados para hacer valer sus derechos ante los tribunales de justicia" ${ }^{\prime 5}$. Es muy importante el alcance global que la Contraloría le da a este principio, aduciendo que debe observarse incluso tratándose de potestades discrecionales. Es más, como sostuvimos en otro artículo ${ }^{59}$, mientras más discrecionales sean las potestades públicas mayores han de ser las exigencias de motivación o fundamentación y de control.

Este principio de motivación se fortaleció con la entrada en vigencia de la Ley $\mathrm{N}^{\circ} 19.880$, la que -en su artículo 15 , inciso primero- consagra el principio de transparencia en términos tales que éste comprendía el acceso a los "fundamentos" de las decisiones que se adopten en un procedimiento administrativo. Asimismo, esa ley, en el inciso segundo del artículo 11, a propósito del principio de imparcialidad, estipula que "los hechos y fundamentos de derecho deberán siempre expresarse en aquellos actos que afectaren los derechos de los particulares, sea que los limiten, restrinjan, priven de ellos, perturben o amenacen su legítimo ejercicio, así como aquellos que resuelvan recursos administrativos".

Ahora bien, en el último tiempo, la Contraloría ha comenzado a enriquecer los elementos que configuran este principio de motivación o la obligación de fundar los actos o resoluciones. Así, ha dicho el organismo contralor que los argumentos de una decisión administrativa deben ser señalados "clara y explícitamente" ${ }^{\prime \prime}$, ha exigido que una Junta Calificadora dicte un nuevo acuerdo "donde consten las diversas razones,

is Por ejemplo, el artículo 133 bis de la Ley Nª 1.336 , Orgánica de la Contraloría General de la República, que exige una resolución "fundada" de la Administración activa para aplicar una sanción administrativa distinta a la propuesta por el organismo contralor cuando éste incoa un sumario administrativo.

36 Dictamen $\mathrm{N}^{\circ} 31.539$, de 2005.

5 Dictamen $\mathrm{N}^{\circ} 29.443$, de 2005.

8 Dictamen $\mathrm{N}^{\circ} 21.948$, de 2003. Ver también Dictámenes $\mathrm{N}^{\circ} \mathrm{s} .28 .349$ y 29.415, ambos de 2002, y 30.176, de 1998.

54 Augusto QUINTANA BENAVIDES: "Control democrático de los organismos de seguridad interior en Chile" (en el libro de Hugo FRÜHLING E., coord.: "Control democrático en el mantenimiento de la seguridad interior", CED, 1997).

(6) Dictamen $\mathrm{N}^{\circ} 40.731$, de 2005. 
motivos y circunstancias concretas que apreció para otorgar la evaluación a un funcionario" ${ }^{\prime \prime}$, los que habrían causado la rebaja de las notas del afectado en los subfactores cuyo puntaje se rebajó; ha reiterado la relación que media entre la obligación de motivar o fundar los actos administrativos y el ejercicio efectivo del principio de impugnación de los mismos ${ }^{62}$ e, incluso, a consecuencia de los principios de publicidad y transparencia, junto con exigir que los fundamentos consten en la decisión, se requiere que tales motivos se informen a los interesados ${ }^{63}$.

Un tema más debatible es si le asiste a la Contraloría calificar los fundamentos de las decisiones que adopte la Administración activa en el ejercicio de sus atribuciones. Así, en el último período ha establecido que los fundamentos deben ser jurídicamente "procedentes", lo cual es dable de ser ponderado por el organismo contralor con motivo del examen de la legalidad del acto o resolución ${ }^{64}$; aunque también ha sostenido lo contrario: “... no compete a Contraloria exigir u ordenar a los concejales que expliciten las razones por las cuales votan en un determinado sentido, ni tampoco, en el caso que establezcan en las actas de las sesiones tales razones, definir la legalidad de un acuerdo de concejo en base al examen de las mismas, ya que ellas son expresión de la libertad de esas autoridades para votar, en ejercicio de un cargo de elección popular, a favor o en contra de una propuesta del alcalde" 65 .

En suma, existe todo un mundo por recorrer para comprender el profundo sentido de esta enmienda constitucional. Lo cierto es que con la nueva disposición constitucional se ha extendido el ámbito de este principio de motivación a todos los "actos o resoluciones", de manera tal que su consagración, parcial, en la citada Ley de Bases de Procedimientos Administrativos, no puede servir de justificación para atenuar el rigor del inciso segundo del artículo $8^{\circ}$ de la Constitución en al ámbito de la Administración del Estado, ni menos respecto de otros órganos del Estado, igualmente obligados. Creemos que para dar fiel y completa vida a este nuevo precepto de la Constitución será menester un profundo cambio en la cultura jurídica de los órganos del Estado y, en general, de los ciudadanos. Ya Platón, en su Mito de la Caverna, nos advertía de las dificultades para cambiar nuestros paradigmas de la realidad. No será fácil asumir el nuevo Estado Democrático y Constitucional de Derecho que nos ofrece la Ley $\mathrm{N}^{\circ} 20.050$, más aún si por mucho tiempo la realidad se ha configurado sólo sobre la base de meras sombras. 


\section{Conclusiones.}

1.- Lo superfluo. La reforma al artículo $3^{\circ}$ parece contener un significado muy menor, a menos que se pretenda culminar el proceso de descentralización política pendiente desde 1810 con el fortalecimiento de las actuales regiones, $o$ incluso con las que se creen en lo venidero a partir de la división de las existentes. Por nuestra parte, seguiremos abogando porque todas las autoridades políticas regionales sean electas democráticamente y para ello se requiere de una nueva reforma constitucional. A su vez, la consagración de los principios de equidad y de solidaridad en el ámbito territorial como Bases de la Institucionalidad tenderá a ser o no superfluo, según sea la proclividad de los tribunales de justicia para aplicarlos en casos particulares.

2.- El contrabando. Ha pasado desapercibida para la deliberación pública, pero la enmienda al artículo $6^{\circ}$ entraña un profundo significado. El constituyente optó sabiamente por entregar el resguardo del orden institucional de la República a todos los órganos del Estado, y no a uno sólo. Es cierto que no siempre esta misión ha sido desempeñada a satisfacción, y en el cuerpo de este escrito criticamos algunas decisiones de la Corte Suprema y del Tribunal Calificador de Elecciones. Sin embargo, es de toda prudencia conferir esta potestad-deber a todos los órganos del Estado, desestimando la inaceptable teoría de entregar a las Fuerzas Armadas la tutela del orden institucional, como también a la aspiración de otros de erigir al Tribunal Constitucional como solitario guardián de la Constitución. Conveniente sería, así creemos, conferir acción pública a los ciudadanos para procurar que los órganos políticos y jurisdiccionales del Estado desempeñen a cabalidad esta nueva misión.

3.- La inocencia. Con la consagración constitucional de los principios de probidad, transparencia y publicidad, como asimismo de la incorporación en las bases de la institucionalidad del principio de motivación de los actos y resoluciones de los órganos del Estado, se ha provocado una enorme y valiosa transformación del Estado democrático y constitucional chileno. Con todo, la real importancia del nuevo artículo $8^{\circ}$ de la Constitución sólo se revelará con el discurrir del tiempo y, a no dudar, es preciso una profunda transformación en la cultura jurídica corporativa de los órganos del Estado, como también de los ciudadanos, para que esta enmienda produzca todos sus frutos.

4.- Lo trascendente. La incorporación de nuevos principios jurídicos entre las Bases de la Institucionalidad refuerza nuestro Estado Democrático y Constitucional de Derecho, ahora con un fuerte sustrato material y no meramente formal. En la medida que nuestra Carta Fundamental recoja innumerables principios y valores, es de esperar que la jurisprudencia -administrativa y judicial- tienda a revisar el estricto paradigma positivista y se desarrolle lo que en otras latitudes se conoce como "jurisprudencia de los valores". 
